\title{
Effect of peripheral canal on growth, survival and production of shrimp (Penaeus monodon) in traditional rice-shrimp culture system in south-west coastal region, Bangladesh
}

\author{
M. L. Islam, M. Moniruzzaman, M. J. Alam and A. F. M. Shofiquzzoha ${ }^{1}$ \\ Bangladesh Fisheries Research Institute, Brackishwater Station, Paikgacha, Khulna-9280, Bangladesh \\ ${ }^{1}$ Bangladesh Fisheries Research Institute, Freshwater Sub-Station, Saidpur, Nilphamary- 5310, Bangladesh
}

\begin{abstract}
The effect of peripheral canal on growth, survival and production of shrimp (Penaeus monodon) has been assessed. The depth of peripheral canal was varied as $0.7 \mathrm{~m}$ (T1) and 0.9 (T2), while the width of canal kept similar $(1.5 \mathrm{~m})$ in all the treatments. There was also a set of experimental plots without peripheral canal (T3). Each treatment had two replications. The experiment was designed for a culture period of 120 days with the stocking density of $3 \mathrm{PL} / \mathrm{m}^{2}$. Results on growth, survival and production performance revealed no significant difference $(p>0.05)$ among the treatments, but apparently higher body weight gain $(23.42 \pm 0.735 \mathrm{~g})$, survival rate $(31.90 \pm 14.959 \%)$ and production $(225.79 \pm 112.140 \mathrm{~kg} / \mathrm{ha}$ ) were obtained from T2 (peripheral canal of $1.5 \mathrm{~m} \times 0.9$ $\mathrm{m})$. In case of survival rate and production, greater deviations were found in all the treatments that indicated differences among the replicated plots in each treatment. The plot under T2 provided highest production of $305.05 \mathrm{~kg} / \mathrm{ha}$ of shrimp with the highest survival rate of $42.48 \%$. It has been an indication of combined effect of depth and canal on the production. Though direct effect of peripheral canal on production was not observed, but strong correlation between water depth on platform area with production $(r=0.935)$; survival rate $(r=0.923)$ and weight gain $(r=0.912)$ was ascertained.
\end{abstract}

Keywords: Effect, Peripheral canal, Production, Tiger shrimp

\section{Introduction}

Coastal aquaculture in the brackishwater ghers of the south-west Bangladesh mainly deals with culture of shrimp (Penaeus monodon) from January-February to June-July when salinity of water remains high and cultivation of rice during low saline period of August to December. Traditionally most of the ghers are rice fields (Shofiquzzoha and Ahmed, 2001) which are topographically facilitated to hold shallow water for rice cultivation. Farmers of the region practice alternate shrimp farming and rice cultivation in the same lands with tidal water facilities. From the very beginning of traditional shrimp farming in early 1960's, most of the farmers used to intake very turbid water in the ghers in each lunar cycle without any treatment. That caused a deposition of considerable amount of silt and organic matter in the gher's bottom (Islam et al, 2002). Due to the continuous practice of such system year after year, ghers bottom uplifted remarkably and turned into shallower water depth. These traditional ghers are no longer suitable for shrimp culture in near future. As because, extended knowledge on shrimp farming and research findings of Bangladesh Fisheries Research Institute indicated that, a moderate water depth ( \pm 1 miter) is essential for keeping the culture environment congenial. The marginal farmers of this region are not interested to increase the bottom depth of gher due to high cost and low production of rice by water logging followed by heavy rain fall during the rice cultivation season.

In these circumstances, development of suitable technique is obviously essential to hold a moderate water depth during the shrimp cultivation season so that shrimp could take shelter during any unfavorable weather conditions, like high temperature. Digging of peripheral canal and/or trench is a proven technique to support fishes in integrated rice-fish farming system (Haroon et al. 1992; Kohinoor et al. 1995; Hung 2001). Like those, digging of peripheral canal might be a helpful option for majority of the shrimp farms in the south-west coastal region to support good water quality and to ensure friendly environment for shrimp. This might also provide extra benefit of integrated ricefish/prawn culture during the low saline period to promote total farm output (Alam et al, 2006). Little work has been done on the suitability of peripheral canal in tiger shrimp culture (Hung 2001) in riceshrimp alternate culture practices in Vietnam. However, information on such practice in Bangladesh is still not available. The results and findings of this paper highlighted the suitability of peripheral canal on the growth, survival and production of shrimp (Penaeus monodon) in the traditional rice-shrimp ghers in south-west Bangladesh. 


\section{Materials and Methods}

To assess effects of peripheral canal on the growth, survival rate and production of shrimp in riceshrimp culture practice, experiment was conducted in the selected farmer's field. The experiment was designed by keeping the width of all canals similar $(1.5 \mathrm{~m})$. The depth of peripheral canal varied from $0.7 \mathrm{~m}$ (T1) to $0.9 \mathrm{~m}$ (T2). There was also a set of experimental plots without peripheral canal (T3). Each treatment had two replications. The experiment was designed for a culture period of 120 days with the stocking density of $3 \mathrm{PL} / \mathrm{m}^{2}$. Preparation of peripheral canals of the experimental plots was done according to the design. The plots were prepared through drying and liming the bottom soil (@250 kg/ha of $\mathrm{Ca}_{2} \mathrm{O}$ ). Plots were introduced with tidal water of $25-60 \mathrm{~cm}$ in depth and treated with phostoxin (@1Tablet/20-25 ton of water) to kill all unwanted animals. Then fertilization was done with urea @1.0ppm, TSP @ 2.0 ppm and MP @0.5ppm for the growth of primary producers. After 7 days of fertilization stocking was done according to the experimental design with hatchery produced shrimp post larvae $(\mathrm{PL})$ having an average weight of $0.008 \mathrm{~g}$. Shrimps were fed with commercial nursery shrimp feed for about 21 days. After that, grow out feed was applied once a day @2-3\% of body weight for the entire culture period. Plots were treated with $0.6-0.8 \mathrm{ppm}$ of dolomite at every 15 days for the entire culture period as a scheduled basis depending on the water $\mathrm{pH}$. Additional liming was also done after every heavy rain fall and on demands. Ponds were fertilized with urea @0.5-1.0 ppm, TSP @1.0-1.2 ppm and MP @0.3-0.4 ppm for the $1^{\text {st }}$ two months of culture depending on the primary productivity. After 90 days of stocking shrimps were selectively harvested by shrimp trap and continued up to 120 days. Final harvesting of shrimp was done by de-watering the plots, then growth, survival and production were estimated. Data were analyzed using Microsoft excel; ANOVA was done to observe the differences among the treatments. Whereas, multiple correlation regression was carried out to observe the relationship between ecological factors, structural modification factors and growth factors of shrimp.

\section{Results and Discussion}

Results of water quality parameters have been graphically presented in Figs. 1-6. Water temperature in all treatments was similar with a sudden drop at $90^{\text {th }}$ day of culture and was within acceptable ranges (Fig. 1). Transparency showed fluctuations in all the treatments during the entire culture period (Fig. 2), but it was within the range of aquaculture (Boyd, 1985) and traditional shrimp culture (Roy et al, 1999; Jung and Co, 1988). Though, water transparency remained within culture range but it was not compatible to the respective water depth. Low water depth permitted adequate light penetration up to the bottom, enhanced the growth of algae on to the bottom sediment and stimulated the growth of rooted aquatic weeds (Najas Spp), which ultimately resulted in the reduction of culture space and deterioration of the culture environment (Boyd, 1985; Rahman, 1992).

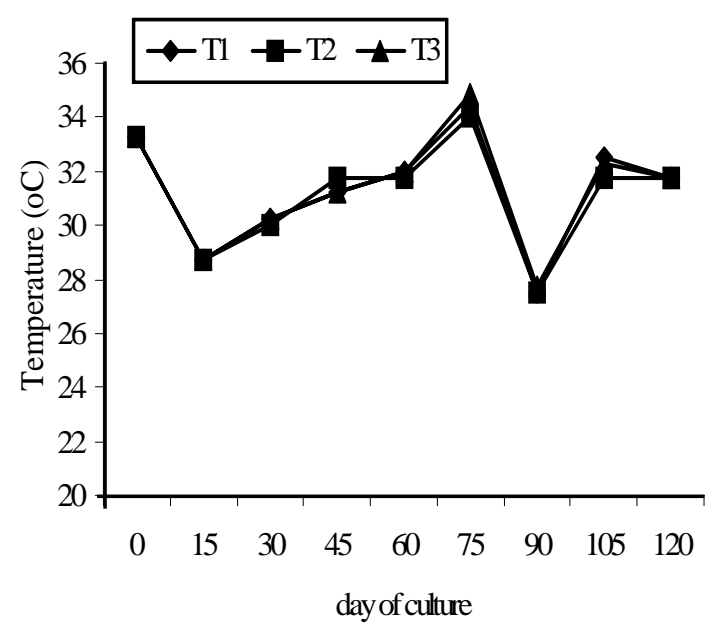

Fig. 1. Water temperature $\left({ }^{\circ} \mathrm{C}\right)$ under different treatments

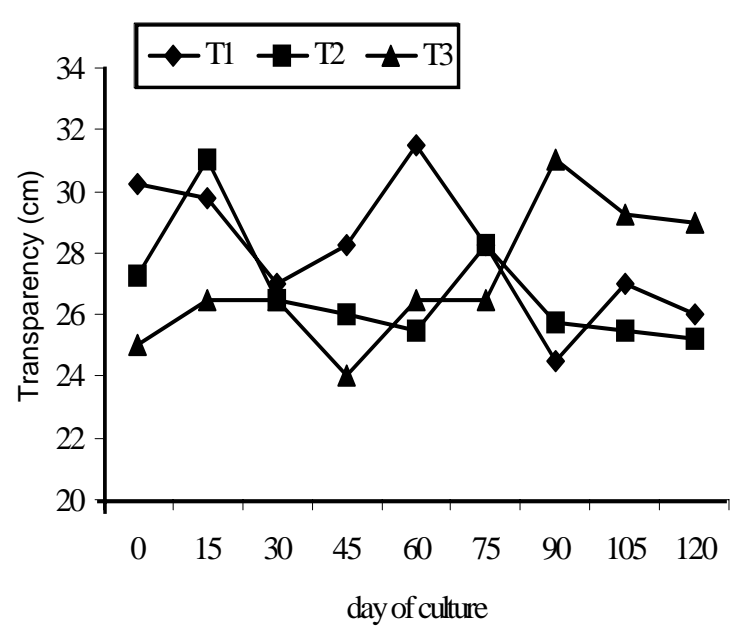

Fig. 2. Transparency (cm) under different treatments 
This is to note that, the experiment was conducted with the variable depth of peripheral canal. It was conducted in the existing farmer's field condition without any modification of the bottom and the experimental plots were situated at different locations. So, there was another intermediate variable of water depth between treatments also among the replicated plots. Water depth on the platform area in the experimental plots was within moderate to shallower (Fig. 3). Water depth on the platform area showed variations and it was significantly different $(p<0.01)$ between T1 and T3, also between T2 and T3, but it was not significantly different $(p>0.05)$ between T1 and T2 (Fig. 3). The overall water depth on the platform area was low to moderate. Krishna (1991) suggested that the elevation of the pond should be maintained in such a level that tidal water can easily enter into the pond and depth of water can be maintained up to $1 \mathrm{~m}$. He also suggested a water depth of $80 \mathrm{~cm}$ to be more suitable for extensive and semi-intensive operation of shrimp culture. Jung and Co (1988) suggested water depth of about $90 \mathrm{~cm}$ for Penaeus monodon culture ponds. So, water depth in the present experiment was not suitable enough for shrimp culture.

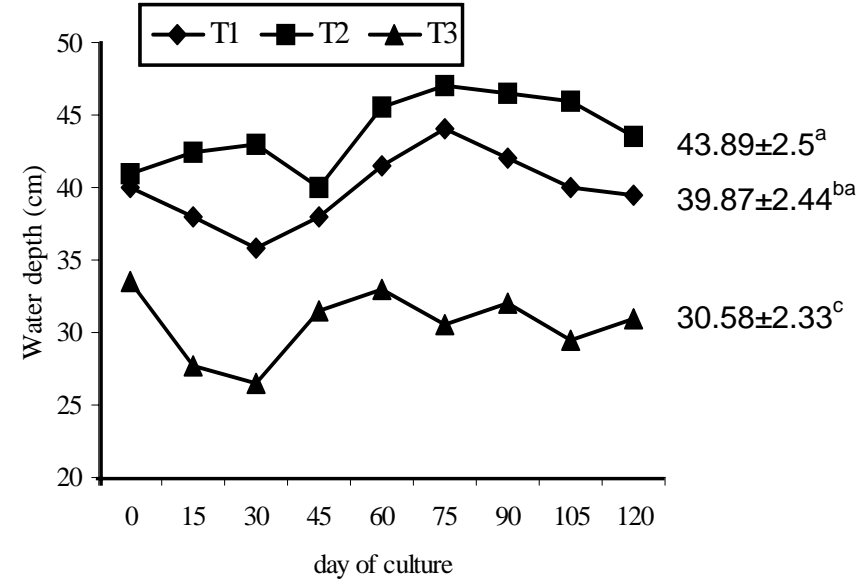

Fig. 3. Level of water depth (cm) under different treatments

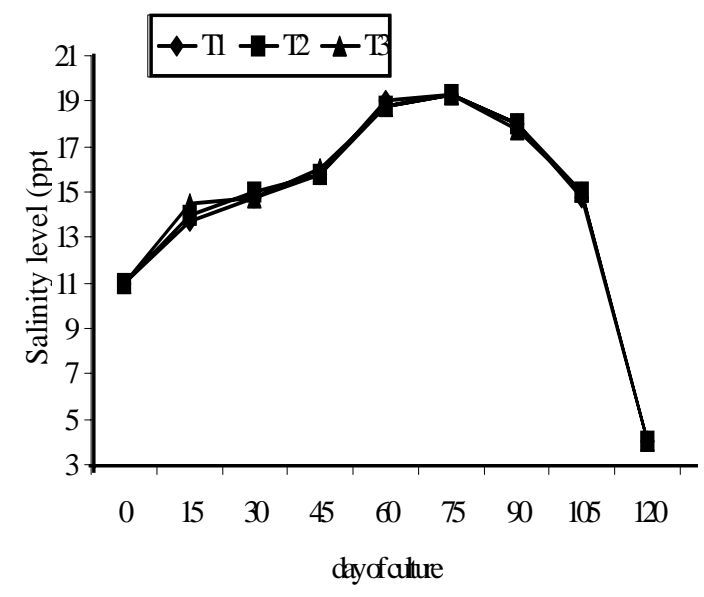

Fig. 5. Dynamics of water salinity (ppt) under different treatments

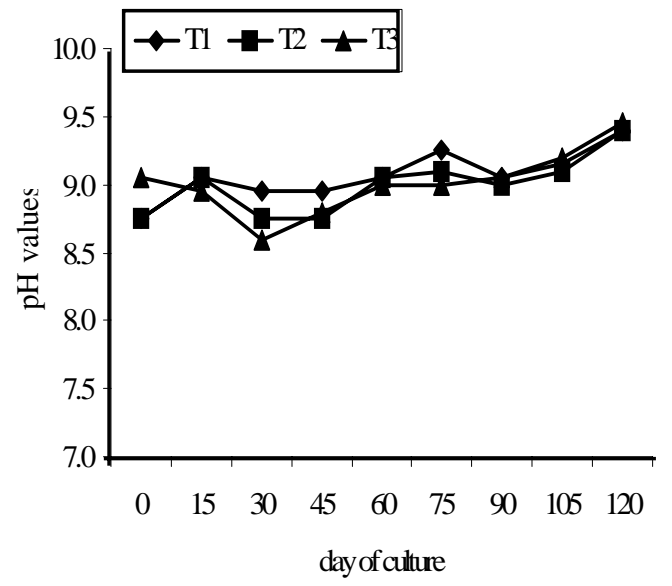

Fig. 4. Water $\mathrm{pH}$ values under different treatments

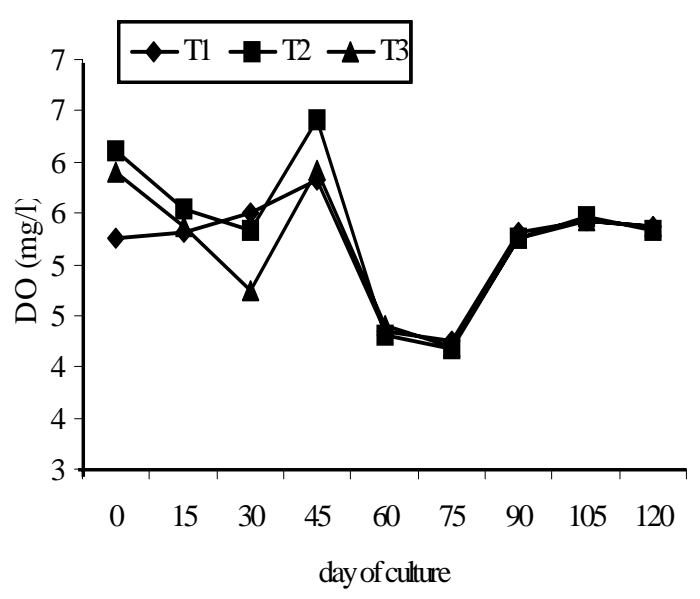

Fig. 6. Dissolved oxygen (mg/l) under different treatments 
Water $\mathrm{pH}$ and salinity showed similar trend in all the treatments (Fig's. 4 and 5). Salinity of water had an increasing trend up to mid May, then dropped suddenly within one month near to zero ppt as the monsoon rain commences. Similar rhythm of water salinity was also observed by Islam et al. (2002); Shofiquzzoha and Ahmed, (2001); Wahab et al. (2003) in the same agro-ecological zone. Water pH increased with the increase of culture duration (Fig. 4) and it might be happened due to releasing of carbon dioxide by the bottom algae and rooted aquatic plants during photosynthesis. Dense growth of aquatic weed and/or dense phytoplankton blooms with high photosynthetic rates can result in elevated $\mathrm{pH}$ levels $( \pm 10.0)$ in the afternoon, causing physical and physiological stress (Boyd and Tucker 1998) and even prawn mortality (Straus et al. 1991). Dissolved oxygen dropped to minimum level at $60^{\text {th }}$ and $75^{\text {th }}$ days of culture (Fig. 6) might be due to higher temperature and followed by cloudy weather, respectively. Variations in water quality parameters, except water depth, were similar among the treatments and were within acceptable ranges for shrimp culture (Chakraborti et al. 1985; Chanratchakool et al. 1995; Hariati et al. 1996).

Results on production performance of shrimp have been presented in Table 1. Final weight gain of shrimp was within 23.42 to $22.46 \mathrm{~g}$ in all the treatments with the highest in T2. Survival rate lied between 24.76 to $31.90 \%$ with the highest value in T2. Highest level of production $(225.79 \pm 112.140$ $\mathrm{kg} / \mathrm{ha}$ ) was obtained from T2 followed by T1 $(182.10 \pm 91.012 \mathrm{~kg} / \mathrm{ha})$ and T3 $(168.36 \pm 80.492 \mathrm{~kg} / \mathrm{ha})$. FCR value was similar in all the treatments. Apparently higher body weight gain, survival rate and production was obtained from T2 (peripheral canal of $1.5 \mathrm{~m} \times 0.9 \mathrm{~m}$ ), but there was no significant difference among the treatments. Though survival rate and production of shrimp was statistically insignificant among the treatments, but higher deviations were found in all the treatments. This indicated differences among the replicated plots in each treatment. Average yield of shrimp in the experiment (225.36 kg/ha) was lower than that of Apud et al. (1984), who reported an average yield of $340 \mathrm{~kg} / \mathrm{ha} / \mathrm{crop}$ at stocking rate of $4-5 / \mathrm{m}^{2}$ in monoculture with supplementary feed and improved water management. Nuruzzaman et al. (2001) found a consistent shrimp production ranging $74-221$ $\mathrm{kg} / \mathrm{ha}$ from their study on the dynamics and diversity of extensive to improved extensive shrimp farming in the same region of Bangladesh. Islam et al. (2005) also reported similar average production of $83-204 \mathrm{~kg} / \mathrm{ha}$ from the shrimp farms stocked at a density of $2-3 / \mathrm{m}^{2}$, following partial stocking and harvesting pattern for an extended culture period of about 180 - 200 days. Though hidden and indirect effect of peripheral canal on the production of shrimp was observed but no significant effect of peripheral canal on growth and production was ascertained. The reason behind this might be due to shallower water depth on the platform area that was unable to support congenial ecological condition. Narrow and short canal area could also be another possible cause. Jung and Co (1988) suggested a water depth of about $90 \mathrm{~cm}$, whereas, Krishna (1991) suggested a water depth of $80 \mathrm{~cm}$ is more suitable for extensive and semi-intensive operation along with bottom trench of 2 to 8 $\mathrm{m}$ wide and $0.7 \mathrm{~m}$ depth covering 20 to $25 \%$ of the total culture area.

Table 1. Growth performance and production of shrimp under different treatments

\begin{tabular}{|l|c|c|c|}
\hline Parameters & T1 & T2 & T3 \\
\hline Final weight $(\mathrm{g})$ & $22.88 \pm 1.103$ & $23.42 \pm 0.74$ & $22.46 \pm 0.93$ \\
\hline Survival rate $(\%)$ & $26.24 \pm 11.99$ & $31.90 \pm 14.96$ & $24.76 \pm 10.92$ \\
\hline Production $(\mathrm{kg} / \mathrm{ha})$ & $182.10 \pm 91.01$ & $225.79 \pm 112.14$ & $168.36 \pm 80.49$ \\
\hline FCR & $1.70 \pm 0.14$ & $1.75 \pm 0.07$ & $1.75 \pm 0.07$ \\
\hline
\end{tabular}

To observe the production-stimulating factors of shrimp, correlation-regression was done among different factors. Among those, three major growth parameters of shrimp were strongly correlated (production, $r=0.935$; survival rate, $r=0.923$ and weight gain, $r=0.912$ ) to water depth (Fig. 7 ). It has indicated that water depth has had the greater influence on the production parameters than the canal depth. Plots with higher water depth could provide relatively suitable ecological factors for living and feeding of shrimp, while shallower depth remain exposed to abrupt fluctuations in water quality during adverse climatic changes like prolonged drought and heavy rainfall, resulting in less survival and low production. This observation was agreed with the findings of Apud et al. (1984), who reported 70.4\% mean survival of shrimp cultured in ponds of $70-100 \mathrm{~cm}$ water depth, compared to that of $37.5 \%$ in pond of $40-70 \mathrm{~cm}$ depth. 


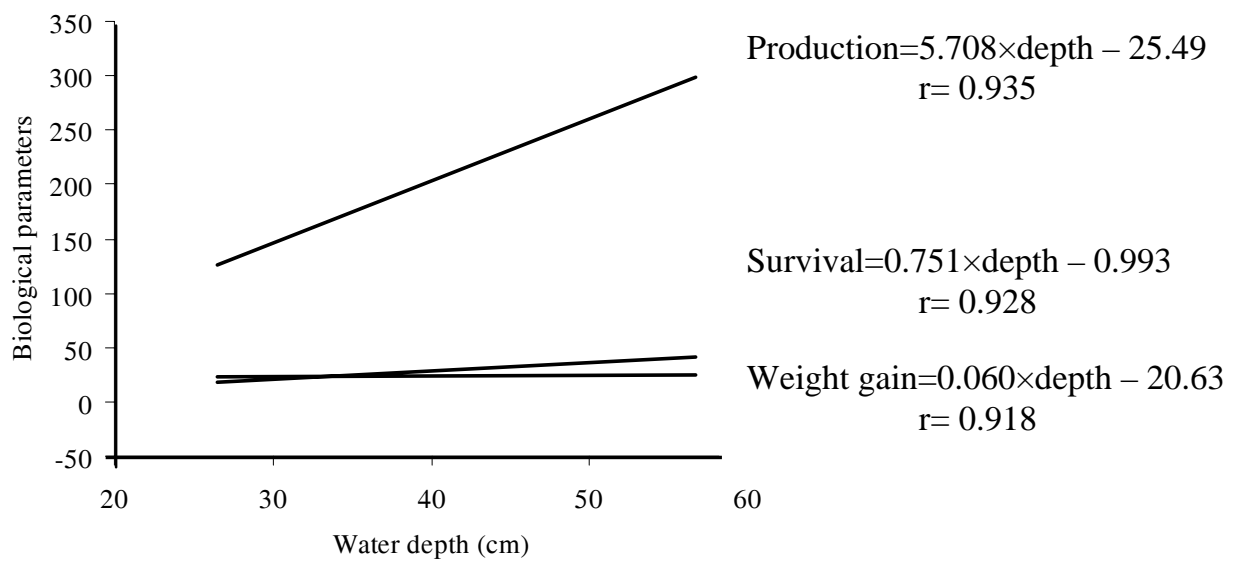

Fig. 7. Correlation-regression between water depth and biological factors of shrimp $(n=6)$

However, in this experiment the differences in growth, survival and production of shrimp were found insignificant among different treatments of canal depth variations. However, results of the experiment were affected by disease in one replicated plots in each treatment having the lower water depth of 25$30 \mathrm{~cm}$. The disease was occurred due to degradation of culture environment during prolonged drought with increased temperature. Growth of bottom algae and rooted aquatic plants might be another possible cause of culture environment degradation. But the other replicated plot of each treatment having a moderate water depth $(40-60 \mathrm{~cm})$ was free from disease also from aquatic weeds. The plot under T2 (higher water depth along with peripheral canal of $0.9 \mathrm{~m}$ depth) provided highest production of $305.05 \mathrm{~kg} / \mathrm{ha}$ of shrimp with the highest survival rate of $42.48 \%$. The overall results and findings of the experiment and respective discussions indicate that, area and depth of peripheral canal have obviously a positive impact on the growth, survival and production of shrimp, but a moderate water depth on the platform is the pre-requisite to support the culture environment during any abrupt change of weather condition.

\section{Acknowledgement}

The authors would like to express their sincere gratitude to the Authority of Bangladesh Fisheries Research Institute for allowing to conduct the research. Shrimp Research Centre Establishment Project in Bagerhat District of BFRI is also acknowledged for financial grants to conduct the research.

\section{References}

Alam, M.J., Saha, S.B., Islam, M.L. and Tuong, T.P. 2006. Potential of rice-fish integration in south-west coastal region of Bangladesh. Progress. Agric., 17(1): 189-199.

Apud, F.D., Gonzales, K. and Deatras, N. 1984. Survival, growth and production of Penaeus monodon (fabricus) at different stocking densities in earthen ponds with flow-through systems and supplemental feeding. Fish. Res. J. Philippines, 6(2): 1-9.

Boyd, C.E. and Pillai, V.K. 1985. Water quality management in aquaculture. Special publication, vol 22. CMRFI (ICAR), Cochin, India, 96p.

Boyd, C.E. and Tucker, C.S. (edited). 1998. Pond aquaculture water quality management. Kluwer Academic Publishers, Norwell, Massachusetts, USA.

Chakraborti, R.K., Ravichandran P., Halder, D.D., Mandal, S.K. and Sanfui, D. 1985. Some physico-chemical characteristics of Kakdwip brackishwater ponds and their influence on survival, growth and production of Penaeus monodon (Fabricius). Indian J.Fish., 32 (2): 224-235.

Chanratchakool, P., Turnbull, J.F., Funge-Smith, S. and Limsuwan, C. 1995. Health management in shrimp ponds. $2^{\text {nd }}$ edition. Aquatic Animal Health Institute, Thailand. 112 p.

Chen, K.J. and Ramos, S.L. 1989. Prawn farming: hatchery and grow-out operation. West point Aquaculture corp., p85. 
Hariati, A.M., Wiadnya, D.G.R., Tanck, M.W.T., Boon, J.H. and Verdegem, M.C.J. 1996. Penaeus monodon (Fabricius) production related to water quality in East Java, Indonesia. Aquacult. Res., 27: 255-260.

Haroon, A.K.Y., Dewan, S. and Karim, S.M.R. 1992. Rice-fish production systems in Bangladesh, In: dela Cruz CR, Lightfoot C, Costa-Pierce BA, Charangal VR, Bimbao MP, editors. Rice-fish research and development in Asia. ICLARM Conf. Proc. 24. p 165-171.

Hung, L.T. 2001. Rice-prawn and rice-shrimp culture in coastal areas of Vietnam, Integrated agriculture-aquaculture: a primer. FAO/ICLARM/IIRR Fisheries Technical Paper No. 407. Rome, FAO. 149 p.

Islam, M.S., Milstein, A., Wahab, M.A., Kamal, A.H.M. and Dewan, S. 2005. Production and economic return of shrimp aquaculture in coastal ponds of different sizes and with different management regimes. Aquacult. Inter., 13: 489-500.

Islam, M.L., Alam, M.J. and Rheman, S. 2002. Impact of shrimp farming on mangrove and estuarine environment of greater Khulna district. Final Report. Bangladesh Fisheries Research Institute, Brackishwater station, Paikgacha, Khulna, Bangladesh. 57 pp.

Jung, C.K and Co, W.G. 1988. Prawn culture, scientific and practical approach. Westpoint Aquaculture Inc., Nable St., Dagupan City, Philippine. 115-125 pp.

Kohinoor, A.H.M. Saha, S.B., Akhteruzzaman, M. and Gupta, M.V. 1995. Suitability of short cycle species Puntius gonionotus (Bleeker) for culture in rice fields. J. Inland Fish. Soc. India, 27(1): 60-64.

Krishna, G.G. 1991. Extensive and semi-intensive culture systems of prawn. In: aquaculture Productivity, V.R.P. Sinha and H.C. Srivastava (eds.). Proceedings of the Symposium on Aquaculture Productivity held in December 1988 under aegis of Hindustan Lever Research Foundation. 201-209 p.

Nuruzzaman, M., Anwari, B., Shahjahan, M. and Moniruzzaman, M. 2001. The dynamics and diversity of the shrimp farming in Bangladesh. Final Report. Fourth Fisheries Project, Shrimp and Coastal Aquaculture Component, Department of Fisheries, Bangladesh. 63 p.

Rahman, M.S. 1992. Water Quality Management in Aquaculture. BRAC Publishing, Dhaka, Bangladesh. 84 p.

Roy, P.K., Ahmed, S.U. and Shofiquzzoha, A.F.M. 1999. Optimization of stocking desnity of environmental-friendly improved extensive shrimp farming system in south-west part of Bangladesh. Bangladesh J. Fish. Res., 3(2):137-143.

Shofiquzzoha, A.F.M. and Ahmed, S.U. 2001. Improving soil, water and productivity in Gher fishery, Final report. Bangladesh Fisheries Research Institute, Mymensingh-2201, Bangladesh. 76 pp.

Straus, D.L., Robinette, H. R. and Heinen, J. M. 1991. Toxicity of un-ionized ammonia and high pH to postlarval and juvenile freshwater shrimp Macrobrachium rosenbergii. Journal of the World Aquaculture Society, 22(2):128-133.

Wahab, M.A., Bergheim, A., Braaten, B., Islam, M.S. and Rahman, M.M. 2003. Observation on some of the environmental parameters of selected shrimp farms in Khulna, Bangladesh. Bangladesh J. Fish. Res., 5 (1): 75-84. 